\title{
Impactos culturais da Primeira Guerra Mundial no Brasil: pequeno debate historiográfico
}

Fecha de recepción: 30/8/2021 Fecha de aprobación: 04/11/2021

\section{Resumo}

Os estudos sobre a Primeira Guerra Mundial têm experimentado uma mudança significativa perceptível a partir de finais do século XX e início do século XXI. Mudanças impulsionadas pela comemoração dos 100 anos da guerra, mas principalmente pela nova História Cultural que trouxe para o plano central de tais estudos os aspectos culturais da guerra, bem como a ideia de que a Primeira Guerra Mundial deve ser pensada em termos transnacionais. Tais ventos de mudança chegaram recentemente ao Brasil, assim, o objetivo deste artigo é fazer uma primeira análise de conjunto da produção brasileira, procurando apontar tendências e levantar algumas questões acerca dos impactos culturais da guerra no Brasil.

Palavras-chave: História cultural, Primeira Guerra Mundial, Impactos, Cultura de guerra, Historiografia

Impactos culturales de la Primera Guerra Mundial en Brasil: un pequeño debate historiográfico

\section{Resumen}

Los estudios sobre la Primera Guerra Mundial han experimentado un cambio significativo, especialmente desde finales del siglo XX y principios del siglo XXI. Cambios impulsados por la conmemoración de los 100 años de guerra, 
pero principalmente por la nueva Historia Cultural, que trajo los aspectos culturales de la guerra al centro de dichos estudios, así como la idea de que la Primera Guerra Mundial debe ser pensada en términos transnacionales. Estos vientos de cambio han llegado recientemente a Brasil, por lo que el objetivo de este artículo es hacer un primer análisis conjunto de la producción brasileña, buscando señalar tendencias y plantear algunas preguntas sobre los impactos culturales de la guerra en Brasil.

Palabras clave: Historia cultural, Primera Guerra Mundial, Impactos, Cultura de guerra,

Historiografía

\title{
Cultural impacts of the First World War in Brazil: a small historiographical debate
}

\begin{abstract}
Studies on the First World War have experienced a significant change, especially from the end of the 20th century and the beginning of the 21st century. Changes driven by the commemoration of 100 years of war, but mainly by the new Cultural History that brought the cultural aspects of war to the center of those studies and the idea that the First World War should be thought of in transnational terms. Such winds of change have recently arrived in Brazil. This article aims to make a first joint analysis of Brazilian production, seeking to point out trends and raise some questions about the cultural impacts of the war in Brazil.
\end{abstract}

Keywords: Cultural history, First World War, Impacts, War culture, Historiography

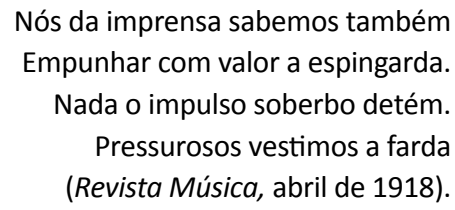

Os versos acima fazem parte da canção de guerra composta por Felix Pacheco e Francisco Braga, dois grandes nomes do cenário jornalístico e musical da capital brasileira, então cidade do Rio de Janeiro. ${ }^{1}$ Compuseram essa canção de guerra especificamente para o Tiro de Imprensa, ou Tiro de Guerra $\mathrm{n}^{\mathbf{0}} 525{ }^{2}{ }^{2}$

1 Félix Pacheco era diretor-proprietário do Jornal Commercio e membro da Academia Brasileira de Letras; Francisco Braga era professor de fuga, contraponto e composição do Instituto Nacional de Música.

2 Os Tiros de Guerra têm sua origem nas Linhas de Tiro que, originalmente, eram clubes de tiro organizados por civis que se espalharam pelo país na primeira década do século XX (McCann, 2007). Especialmente durante a atuação de Hermes de Fonseca como ministro da guerra (1906-09), os Tiros de Guerra se expandiram pelo país e em 1917 foram militarizados e subordinados à Diretoria Nacional do 
formado recentemente por representantes de imprensa, num momento de crescente mobilização da sociedade brasileira. Afinal, em outubro de 1917, o Brasil (que havia optado pela neutralidade desde o início da Grande Guerra em julho de 1914) declarou guerra às potências centrais e preparava-se para enviar uma missão médica para a Europa. ${ }^{3}$ Além disso, uma nova ofensiva alemã retomou territórios, reafirmando incertezas sobre o destino do conflito. ${ }^{4}$

Todavia, a pequena participação brasileira na Primeira Guerra Mundial e o fato de que os campos de batalha residiam do outro lado do Atlântico contribuíram para que, durante muito tempo, tais temas fossem alvo apenas de estudos com foco nos aspectos militares, políticos (geralmente no âmbito da política externa brasileira) e econômicos. Tendências também presentes no contexto europeu do pós-guerra, pois, somente nos anos 1960 apareceriam análises de cunho social e marxista. Nos anos 1990 entraram em cena estudos que procuram repensar a guerra do ponto de vista cultural, uma produção que mudou o rumo das pesquisas referentes à Primeira Guerra numa escala global (Correia, 2014). Tais ventos chegaram ao Brasil, implicando o ressurgimento do interesse de pesquisadores acerca dos impactos culturais da guerra no país. Assim, a partir da análise de uma historiografia clássica e outra bem recente, temos como objetivo realizar um primeiro esforço no sentido de pensar suas principais contribuições e questões.

0 texto que se segue foi dividido em três partes: a primeira parte tem como objetivo fazer breves apontamentos acerca das mudanças recentes na escrita da história da Primeira Guerra Mundial, a segunda parte relaciona tais alterações com a produção brasileira acerca dos impactos culturais da guerra no Brasil e a terceira parte refere-se à conclusão, onde procuramos resumir nossos principais achados.

\section{A "virada cultural" nos estudos sobre Primeira Guerra Mundial}

No livro em que debate as alterações no ofício do historiador no tempo presente, Henry Rousso constrói de forma magistral o impacto devastador da guerra de 1914:

A Primeira Guerra Mundial não traz senão destruição (...). De uma crença em um progresso racional, contínuo, dominado, passa-se em alguns anos ao sentimento quase geral de um mundo refém do caos, de um tempo marcado pela descontinuidade de uma história repentinamente (...) fora de si. (2016: 100).

Tiro de Guerra, dirigida por um coronel do Exército brasileiro (Albino, 2015: 56).

3 O governo brasileiro enviou “(...) uma Divisão Naval para patrulhar a costa ocidental da África; uma missão médica militar e um grupo de oficiais do Exército para a França; e um grupo de aviadores navais para treinamento e posterior atuação em combate na Grã-Bretanha, Itália e EUA". (Daróz, 2016: 13).

4 Somente em julho de 1918, o exército aliado, auxiliado por batalhões norte-americanos, começou a impingir uma série de derrotas às potências centrais. (Sondhaus, 2014: 454-455). 
Porém, a violência de 1914 e seus efeitos perversos teriam sido relegados praticamente ao esquecimento devido aos impactos da guerra de 1939. A Segunda Guerra Mundial e seus horrores centralizaram as pesquisas, produzindo inclusive uma desconexão entre os dois eventos, o que Rousso chamou de "ignorância recíproca", pois especialistas das duas guerras ignoravam as múltiplas conexões entre os dois eventos. Nesse sentido, a nova historiografia sobre a Primeira Guerra, além de reconectar as guerras, trouxe à luz a violência da guerra de 1914, inédita para a humanidade, que foi redescoberta pela produção dos anos 1990-2000. (Rousso, 2016: 275).

Alguns trabalhos foram essenciais para essa "virada cultural". A historiadora portuguesa Silvia Correia destaca, por exemplo, os trabalhos de Mario Isnenghi, George Mosse, Paul Fussell e Samuel Hynes. ${ }^{6}$ Especialmente os dois últimos, cujos trabalhos no âmbito da história cultural da guerra, ao tomar como referência as construções memoriais dos combatentes, demonstraram claramente a importância de se perceber a Primeira Guerra como "uma ruptura fundamental na era moderna", algo que seria "incompreensível precisamente sem a intensificação dos pontos de vista da história cultural" (Correia, 2014: 657).

Esse alargamento de percepções sobre a guerra, ressaltando seus aspectos culturais, foi influenciado por mudanças traçadas a partir de uma nova História Cultural, o que possibilitou, por exemplo, se pensar novos objetos de pesquisa.' No caso da Primeira Guerra, como bem ressaltaram Olivier Compagnon, Camille Foulard, Guillemette Martin e María Inés Tato na introdução do livro La Gran Guerra en America Latina. Una História conectada, isso significou a ampliação de estudos sobre a guerra para além do front e trouxe à luz não apenas os impactos da guerra sobre a população civil, mas a possibilidade de estudá-los em países que não participaram efetivamente do conflito, ou que tiveram uma participação muito diminuta, como é o caso do Brasil (2018: 11).

Nesse sentido, os anos 1990 trouxeram um número significativo de novos trabalhos e iniciativas no âmbito dos estudos sobre a Primeira Guerra, como as produções de Jean Jacques Becker e da equipe do Historial de Péronne (inaugurado em 1992). No âmbito dessa pesquisa, os estudos de Stéphane

5 Essa é considerada a terceira fase da escrita da história da Primeira Guerra Mundial. No livro Penser la Grande Guerre (2004), Antoine Prost e Jay Winter resumem a historiografia da guerra em três fases: a primeira fase teve caráter militar e diplomático, a segunda focou aspectos sociais e a terceira relacionou cultura e sociedade. Segundo os autores, é possível perceber uma clara ruptura entre a primeira e a segunda fases, já a passagem da segunda para a terceira é mais sutil, apresentando mais continuidades do que rupturas.

6 A autora cita como exemplo as obras de Mario Isnenghi (1970), Il mito della Grande Guerra: da Marinetti a Malaparte; George Mosse (1990), Fallen Soldiers: Reshaping the Memory of the World wars; Paul Fussell (1975), The Great War and Modern Memory; e Samuel Hynes (1991), A War Imagined. The Great War and English Culture.

7 Durante boa parte do século XX é possível verificar a predominância de uma historiografia marxista de cunho social e econômico na qual os aspectos culturais tinham um papel coadjuvante. Segundo Antoine Prost: "A cultura não estava verdadeiramente integrada à síntese histórica senão sob a forma de dependência, de uma tradução, ou inculcada em proveito da classe dirigente" (1998: 127). Porém, tal quadro se altera nas últimas décadas do século XX com a emergência de uma nova História Cultural de caráter interdisciplinar, trazendo colaborações da Antropologia e da Linguística, e em diálogo direto com o "retorno" da história política (Barros, 2011). 
Audoin-Rouzeau e Annette Becker (2000), que definiram o termo "cultura de guerra", auxiliaram deveras no exercício de toda uma geração de historiadores empenhados em pensar a guerra, antes de tudo, como um ato cultural. No livro que se tornou uma referência nos estudos culturais sobre a guerra, Audoin-Rouzeau e Becker procuram responder a uma questão básica: porque é que os europeus consentiram, durante cinco anos, passar por tanto sofrimento e sacrifício sem se revoltar? A permissão para que o conflito se prolongasse possibilita classificá-lo como uma "guerra do consentimento", justificada pela luta da civilização contra a barbárie, cristalizando uma verdadeira "cultura de guerra", impregnada de raiva para com o inimigo. Algo intensamente trabalhado pelas elites intelectuais alemães, francesas e inglesas, que se empenharam em comprovar tais representações e valores através de seus escritos. A argumentação apresentada no campo de batalha cultural, que era a base da propaganda levada a cabo pelos beligerantes, se organizava em torno dos conceitos de civilização e barbárie. Por sua vez, Antoine Prost e Jay Winter trataram de demarcar definitivamente a importância da cultura nos estudos da guerra, apontando-a como front pioneiro de pesquisa sobre a Primeira Guerra Mundial, ao possibilitar pesquisas acerca dos impactos da guerra em outras frentes como as artes, ciências e literatura, por exemplo (2004: 48).

A propaganda é um dos temas mais explorados pelos pesquisadores, já que concentra boa parte da argumentação apresentada no campo de batalha cultural e sua importância pode ser compreendida no âmbito da "guerra total", ou seja, no engajamento de todos os meios necessários para derrotar o inimigo, como bem destacou Troy Paddock, autor de um dos trabalhos mais importantes sobre o tema. Paddock (2014) define propaganda como um processo de negociação, e não de manipulação, que mobiliza certos valores e ideias, cuidadosamente pensados e selecionados para uma determinada audiência, tomando como base as tendências da opinião pública. Nesse sentido, em todas as nações beligerantes a propaganda governamental, as artes e o entretenimento foram explorados em níveis diferentes de consciência (fosse para glorificar a pátria, demonizar o inimigo ou estimular apoio aos objetivos expansionistas de guerra), produzindo uma intensa politização da arte, o que tornou extremamente difícil para artistas, músicos e intelectuais afirmarem uma neutralidade, ou indiferença, em relação ao conflito (Roshwald e Stites, 1999).

Resumindo, segundo Becker (2014), a criatividade literária e artística do período, que acompanhou intensamente os anos da guerra e do pós-guerra, entrou à força no campo dos estudos históricos sobre a Primeira Guerra. Contudo, não foi acompanhada de estudos sobre a música pela ausência de um controle por parte dos historiadores da linguagem musical. Por isso, coletâneas e trabalhos recentes de historiadores e musicólogos procuraram preencher tal lacuna ao integrar e analisar a multiplicidade de manifestações da guerra no cenário musical e da música no campo de batalha. ${ }^{8}$ Nesse universo de novas publicações, merece destaque o trabalho do musicólogo norte-americano 
Glenn Watkins (2003), que analisa como a música na Primeira Guerra Mundial (na Europa e nos Estados Unidos) atuou como um poderoso veículo de propaganda, promovendo uma complexa rede de representações de poder e identidade.

Enfim, considerando que a neutralidade também é uma posição político-cultural, que torna obrigatório repensar identidades e valores, representações da sociedade e de sua história, na procura das razões para se manter neutro, ou apoiar um dos lados em conflito, estudos sobre os impactos culturais da guerra em países neutros adquirem novos significados e importância. Retomando a introdução do livro La gran guerra..., percebemos que os impactos da guerra na América Latina, além de pouco estudados, eram percebidos pelo prisma de análises diplomáticas e militares que tinham como ponto de partida uma leitura eurocêntrica do conflito. Nesse sentido, a "virada cultural" nos estudos sobre a guerra, também adquiriu o sentido de uma "virada global", pensada a partir das noções de "historia cruzada, historia conectada, historia transnacional e historia global” (Compagnon et al., 2018: 11), incitando a construção de objetos para além das fronteiras nacionais e integrando a América Latina ao elenco de possíveis trabalhos sobre a guerra, a partir de uma questão central: " ¿es posible trazar los contornos de lo que habría sido una experiencia latinoamericana de la Gran Guerra?" (Compagnon et al., 2018: 12).

Alguns exemplos desta já considerável produção são os trabalhos de Mariano Siskind (2015), María Inés Tato (2008 e 2014), Patricia Veja Jiménez (2013), Philip Dehne (2014), Olivier Compagnon (2014) e Stefan Rinke (2017), que procuram enfatizar a importância do conflito nos debates nacionalistas perceptíveis nos anos da guerra e nas décadas de 1920 e 1930. Esses trabalhos procuram demonstrar não apenas a importância da América Latina no cenário da Primeira Guerra Mundial, mas também os impactos da conflagração nas construções de suas identidades nacionais. Como bem analisou Mariano Siskind (2015), a guerra rompeu com a ordem geral de significados, amplificando um campo de discurso transatlântico no qual intelectuais latino-americanos, de vários extratos ideológicos, procuraram elaborar respostas para as interpelações civilizacionais por ela colocadas. Porém, esse discurso não é, de forma alguma, harmônico e homogêneo; exemplo disso é a formação no Brasil, na mesma época (meados de 1915), de uma Liga Brasileira pelos Aliados e uma Liga Brasileira Pró-Germânia. ${ }^{10}$ Finalmente, trata-se de um debate que ganhou forças nas primeiras décadas do século XXI com consideráveis repercussões na historiografia brasileira."

9 Para trabalhar esses conceitos, os autores utilizaram como referência as obras de Anthony Hopkins (2006), Global History. Interactions between the Universal and the Local; Pamela Crossley (2008), What is global history?; Diego Olstein (2014), Thinking History Globally.

10 A Liga Brasileira Pró-Germânia foi criada em junho de 1915, por iniciativa da colônia alemã no Rio de Janeiro (Claro Pires, 2020).

11 Realizamos uma pequena pesquisa nas plataformas Catálogo de Teses e Dissertações (https://catalogodeteses.capes.gov.br) e Portal Domínio Público (http://www.dominiopublico.gov.br) com objetivo de ter uma ideia mais apurada da produção mais recente. 


\section{Impactos culturais da Primeira Guerra no Brasil: principais temas e debates}

Publicado no início dos anos 1990, o trabalho de Nicolau Sevcenko, Orfeu extático na metrópole: São Paulo, sociedade e cultura nos frementes anos 20, era categórico ao praticamente negar os impactos culturais da Primeira Guerra no Brasil:

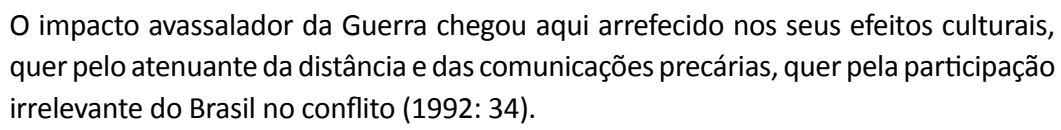

Perspectivas diferentes podem ser encontradas em outros trabalhos também do início dos anos 1990. Em seu livro clássico, A questão nacional na Primeira República, Lúcia Lippi Oliveira ressalta a importância da Primeira Guerra Mundial na "revisão dos padrões intelectuais brasileiros", pois, nos anos que sucederam sua eclosão, reavivou-se a necessidade de pensar o Brasil "do ponto de vista brasileiro" (1990: 146), trazendo a questão nacional para a pauta dos debates e alterando inclusive o significado do nacionalismo em prática até o momento, de tipo ufanista. ${ }^{12} \mathrm{O}$ momento era de crítica, ponto perceptível nos programas de diferentes movimentos nacionalistas que se organizaram durante e após a Primeira Guerra.

Outro trabalho clássico que aborda a questão é o de Marly Motta (1992), $A$ Nação faz 100 anos: a questão nacional no Centenário da Independência. A autora ressalta o forte impacto que a Primeira Guerra teve na intelectualidade, trazendo à tona a urgência de se pensar os problemas do país. Assim, apesar da divisão entre aliadófilos e germânicos, ao final do conflito predominou a sensação de falência da civilização belle époque como modelo de modernidade a ser alcançada.

As diferenças entre trabalhos cronologicamente tão próximos remetem a uma historiografia que apenas recentemente empreendeu um trabalho de revisão do impacto e lugar da Primeira Guerra na história brasileira. Segundo Rogerio Souza Silva e Silvia Capanema de Almeida (2018), durante praticamente todo o século XX, a guerra foi representada apenas como uma divisão cronológica que marcaria alterações nas relações de poder entre o Brasil e outros países e teria introduzido mudanças econômicas. Somente na década de 1990 e início dos anos 2000 surgiram novas abordagens que incorporam a guerra sob um novo marco, nos quais podemos incluir os textos de Lippi e Motta, pensada como um momento de ruptura, não apenas econômico e político, mas também cultural, recebendo um lugar de maior destaque e importância na historiografia brasileira (Silva y Almeida, 2018: 267-268).

12 A obra de Affonso Celso, Porque me ufano do meu país, escrita para as Comemorações do IV Centenário do Descobrimento, em 1900, serviu de base para esse tipo de nacionalismo cujas características essenciais eram a maximização das qualidades da natureza e do homem brasileiro (Lippi Oliveira 1990: 149).

13 Alguns exemplos dessa mudança citada pelos autores são os trabalhos de Thomas Skidmore (2012), 
Faltavam, todavia, estudos mais aprofundados que pudessem dimensionar os impactos culturais da guerra, bem como o grau de mobilização da sociedade brasileira com relação ao evento. Um exemplo disso é o fato de que a Liga Brasileira pelos Aliados, ${ }^{14}$ um dos maiores exemplos de mobilização da sociedade brasileira, que acompanhou atentamente o desenrolar da conflagração e procurou inclusive influenciar a tomada de posição do governo brasileiro, só recebeu um estudo de fôlego recentemente. Refiro-me à dissertação de mestrado de Livia Claro Pires, publicada em 2019 sob o título Intelectuais nas Trincheiras, que foi vital para demonstrar como os discursos em prol de uma causa ou outra não eram apenas de cunho político ou econômico, mas essencialmente cultural. Segundo Lívia Claro, a associação, formada pela elite cultural do país, se atribuiu o caráter de representante da opinião pública brasileira no que se referia à guerra, mobilizando-a no sentido de absorver a guerra como um "problema nacional". Para a autora, o "projeto de nação" apresentado pela Liga - "uma nação branca, afinada com o modelo político liberal europeu e com a tradição cultural latina" (2013: 153), se afinava com o discurso orientado pelas premissas da propaganda aliada enviada aos países neutros. Atualmente, Claro (2020) continua trabalhando com os impactos da Primeira Guerra no Brasil e tomou como objeto de estudo os discursos germanófilos construídos por intelectuais brasileiros como o objetivo de compreender suas relações com o pensamento nacionalista em voga no momento.

Nesse sentido, cabe destacar que um primeiro esforço para clarificar esse cenário, palco de intensos debates entre aliadófilos e germanófilos, foi empreendido pelo historiador francês Olivier Compagnon (2011). ${ }^{15} 0$ estudo comparativo entre Brasil e Argentina traz como hipótese central a ideia de que a Primeira Guerra Mundial constituiu um momento particular na história do século XX latino-americano, ao contribuir para o questionamento da cultura cosmopolita vinculada até então. E assim, para o aprofundamento de uma reflexão duradoura acerca de uma nova identidade nacional, independente dos "modelos europeus", considerados inadequados à realidade latino-americana. De forma que, a guerra teria importância considerável nessa "crise de identidade", sendo "uma das matrizes da renovação dos debates sobre a construção nacional no outro lado do Atlântico" (2014: 19). Compagnon percebe que a ideia dominante, segundo a qual o conflito representaria o enfrentamento entre a civilização francesa e a barbárie alemã, é aos poucos substituída pela imagem de um desmoronamento da civilização europeia, e consequentemente, "dos modelos segundo os quais foram construídas as modernidades latino-americanas a partir das Independências" (291).

Preto no Branco. Raça e nacionalidade no pensamento brasileiro (1870-1930), y Hebe Mattos (2012), "Além do Voto: cidadania e participação política na Primeira República brasileira".

14 A fundação da Liga Brasileira pelos Aliados em março de 1915 marcou claramente a preferência pela causa das nações da Entente, sendo escolhido para seu presidente Rui Barbosa, e para vice, o ensaísta e crítico literário José Verissimo. (Claro Pires, 2013).

15 Olivier Compagnon (2011), Guerre mondiale et construction nationale. Argentins et Brésiliens face au suicide de l'Europe (1914-1939). A versão em português da tese foi publicada em 2014, considerando as dificuldades de acesso e leitura do texto original em termos de impacto na historiografia brasileira tomamos como referência o texto publicado em 2014, O adeus à Europa: a América Latina e a Grande Guerra. 
Em um primeiro momento, é perceptível que ambos os estudos (guardadas as devidas proporções) chegam a conclusões diferentes: enquanto o trabalho de Claro sobre a LBA acaba por reafirmar os vínculos com a civilização europeia, o estudo de Compagnon percebe pontos de tensão, que aponta no sentido contrário, ou seja, de ruptura com eles.

Movimentos díspares que também percebemos quando nos debruçamos sobre o cenário musical da capital brasileira. Entre 2015 e 2017, desenvolvemos uma série de estudos sobre os impactos da Primeira Guerra Mundial no cenário musical carioca que tiveram como objetivo analisar o lugar que a música ocupou no debate nacionalista, ${ }^{16}$ desencadeado pelas repercussões da guerra na capital do país através de eventos-chave, como por exemplo os eventos culturais promovidos pela LBA entre os anos de 1915 e 1917 e o período de permanência no Brasil do músico francês Darius Milhaud, como adido cultural da França, junto ao embaixador Paul Claudel, entre fevereiro de 1917 e outubro de 1918.

Na análise em conjunto de tais eventos percebemos a participação de importantes músicos brasileiros na causa aliada, bem como o engajamento de notáveis do cenário literário, artístico e político nos eventos da LBA, que foi, definitivamente, a primeira organização brasileira a estimular o debate acerca do posicionamento brasileiro no cenário de conflito, justificando o seu apoio aos aliados numa aliança cultural, manifesta no repertório literário e musical de seus eventos. Através de tais eventos, podemos concluir que a atuação da Liga 'fertilizou' a opinião pública brasileira numa direção pró-aliados, através da mobilização de um sentimento comum de latinidade, reforçando esteticamente os laços entre a música brasileira e francesa. Assim, o jovem músico francês, Darius Milhaud, encontraria terreno fértil para atuar, através da organização de uma série de eventos beneficentes e das relações que construiu com importantes músicos brasileiros, preencheu uma lacuna deixada pela LBA que, a partir de 1917, diminuiu consideravelmente sua atuação através de eventos culturais.

A partir dos concertos por ele organizados, ou que contaram com sua participação, ou apenas com a divulgação de sua obra, é perceptível que a atuação Milhaud contribuiu para o aprofundamento da segmentação entre o mundo germânico e o latino, e dos laços que ligavam a música erudita brasileira à francesa. Portanto, deve-se pensar sua atuação como estreitamente vinculada à propaganda e mobilização cultural francesa empreendida durante a guerra em países neutros. 0 que foi identificado através da análise dos repertórios dos concertos, mas também no fato de que eram organizados com o objetivo de angariar fundos para soldados feridos, ou algum outro grupo desamparado pela guerra.

16 Tais estudos foram patrocinados pelo Programa de Incentivo à Produção do Conhecimento Técnico e Científico na Área da Cultura, desenvolvido pela Fundação Casa de Rui Barbosa (FCRB), dentro de uma temática pré-definida intitulada "Impactos culturais da Primeira Guerra Mundial no Brasil" e supervisionados pelo pesquisador da casa, Marcos Veneu.

17 A pesquisa foi publicada no seguinte artigo: Luciana Fagundes (2017), “Música e guerra: impactos da Primeira Guerra Mundial no cenário musical carioca". Apresentamos aqui um resumo de suas principais conclusões. 
Outro estudo deveras relevante e que agrega questões significativas ao debate sobre os impactos culturais da guerra no Brasil é o livro de Stefan Rinke, publicado em 2017. ${ }^{18} 0$ historiador alemão reforça a importância da guerra como elemento transformador não apenas de ideias, mas da realidade social na América Latina, todavia, ressalta que, diferentemente do que ocorreu na Europa, os anos da guerra não representaram para esses países a catástrofe que deu origem ao século XX. ${ }^{19}$ Rinke também alerta para outro ponto: se é notória a perda de confiança dos países latino-americanos nos modelos europeus de modernidade e civilização (demandando uma reorientação de identidades a nível nacional e regional), “(...) é necessário perguntar até que ponto a guerra pode ter fortalecido ou enfraquecido tendências específicas" (2017: 5), ou seja, é imprescindível estarmos atentos à heterogeneidade de discursos que emergem tanto ao longo da guerra, quanto no imediato pós-guerra, cuja análise tem sido feita através da imprensa, principal canal de divulgação de uma expressiva propaganda de guerra. Segundo Rinke, a propaganda de guerra levada a cabo pelas nações beligerantes através da imprensa e de novas mídias, como o cinema e a fotografia, foi especialmente abundante nas Américas justamente porque abrigavam o maior número de nações neutras. Sua ampla circulação gerou, por exemplo, uma forma sem precedentes de ódio radical para com os envolvidos no conflito, especialmente os impérios centrais, Alemanha e Áustria-Hungria, devido à maior facilidade de penetração da propaganda aliada, mas não somente. Assim, é de suma importância atentarmos para a produção brasileira sobre o tema imprensa e propaganda de guerra.

As noticiais sobre a Grande Guerra fluíam a um ritmo frenético pelos cabos submarinos e preenchiam rapidamente as páginas de jornais e revistas, acompanhadas de desenhos ou fotografias. Junto às associações ou ligas criadas pela intelectualidade brasileira, a imprensa assumiu o papel de difundir representações do conflito; uma produção de forma alguma homogênea e recheada de embates entre aliadófilos, neutrais e germânicos.

Contudo, a produção brasileira sobre o tema era praticamente nula e apenas em 2003, com o livro do jornalista Sidney Garambone, teríamos alguma ideia sobre como a imprensa carioca representou a guerra em suas páginas. Focado nos jornais Correio da Manhã e Jornal do Commercio, Garambone concluiu que a imprensa carioca não se posicionou imediatamente ao lado dos aliados, adotando inicialmente uma posição neutra em relação ao conflito, assim teríamos duas fases ao longo da guerra: uma primeira fase em que a imprensa defendia a neutralidade brasileira e se apresentava como neutra em relação ao conflito e uma segunda fase, na qual o posicionamento pró-aliado tornou-se explicito.

18 O livro analisa os impactos sociais, políticos, econômicos e culturais da guerra na América Latina, dedicando-se especialmente aos países com maior influência na região como Argentina, Brasil, Chile, Colômbia, Peru e México.

19 "This study, however, has shown that the war was not just a catalyst, but a transformer that brought change from the realm of ideas to the social realities of the streets. To be sure, the war years in Latin America did not represent the great 'seminal catastrophe of the twentieth century', as they did in Europe" (Rinke, 2017: 261). 
O trabalho chamou a atenção para a importância da imprensa no momento, além de ressaltar a pluralidade de periódicos, seu crescimento e modificações editoriais. Todavia, deixava de fora muitas questões.

A princípio, considerando as limitações do estudo de Garambone, era possível afirmar que suas conclusões não poderiam ser generalizadas, nem para a imprensa carioca, nem para a imprensa nacional. Apesar de Garambone discorrer sobre as alterações no jornalismo brasileiro do período, restavam muitas lacunas, como por exemplo, a atuação das agências de notícias ao longo da guerra, afinal, eram elas as encarregadas de fornecer praticamente todas as informações e por fim, porém, não menos importante, restava compreender o funcionamento da censura no Brasil durante a guerra, que não se estendeu apenas à imprensa, mas também aos telégrafos, correspondências privadas entre outros, e se articulou intimamente a uma rede de censura articulada a partir dos países beligerantes (Arouca, s.d.). Na segunda década do século XXI, uma série de estudos procurou responder a tais questões, sendo o estudo da imprensa brasileira durante a Primeira Guerra um dos temas que mais chamou a atenção dos pesquisadores.

Nesse sentido, com relação às alterações no formato dos jornais cariocas com intuito de se adequar ao abundante noticiário acerca do conflito, temos o trabalho de Aline Andrade Pereira que pesquisou quatro grandes jornais cariocas - Correio da Manhã, Jornal do Brasil, O Paiz e Jornal do Commercio. Segundo Pereira (2013), a partir do assassinato do príncipe herdeiro do Império Austro-Húngaro, Francisco Ferdinando, estopim da Primeira Guerra Mundial, em junho de 1914 até a declaração de guerra da Áustria à Sérvia no final de julho, foi possível observar que os títulos das matérias sobre a guerra se transformavam aos poucos em manchetes, criando uma nova formatação. Um exemplo foi a utilização, pela primeira vez, da expressão "Europa em guerra" pelo Jornal do Brasil, no dia 2 de agosto, logo em sua primeira página. A autora concluiu que o desafio de noticiar diariamente a guerra acabou por alterar a diagramação dos jornais.

Sobre a atuação das agências de notícias, o trabalho do jornalista Matias Molina, apesar de não focar exclusivamente o período da guerra, contribui para termos uma melhor noção da importância que adquiriu o controle de informações, já que uma das primeiras atitudes dos aliados com relação a América Latina, no início da Primeira Guerra Mundial, foi cortar o cabo telegráfico submarino que estabelecia, desde 1909, comunicações entre a Alemanha e o continente latino. Tal ação reforçava o monopólio que a agência de notícias Havas tinha sobre os jornais brasileiros. ${ }^{20}$ Segundo Matias Molina, logo no começo da guerra, Jorge Mitre, diretor e também membro da família proprietária do jornal argentino La Nación, teria pedido a Havas que transmitisse também comunicados alemães e austríacos. A resposta da agência teria sido:

20 A Agência Havas, fundada em 1835, pelo francês Charles-Louis Havas foi a primeira agência mundial de notícias, contando com correspondes próprios na França e nas principais capitais europeias (Molina, 2015). 
“Nous sommes françaises” (2015: 304). No caso, ressalta Molina, mesmo se a agência quisesse atender às demandas de Mitre, a censura francesa não teria permitido a transmissão de comunicados de países inimigos. De qualquer forma, estava clara a prioridade da agência de notícias: ajudar seu país a ganhar a guerra. Não estava em pauta realizar uma cobertura neutra do conflito e assim como a cavalaria ou a frota naval, a informação ou desinformação também eram armas de guerra.

Se as agências de notícias não eram neutras, parte da imprensa brasileira seguiu a posição do governo brasileiro e optou pela neutralidade. Nesse sentido, o pequeno estudo de André Felipe Cândido da Silva sobre os artigos do médico Henrique da Rocha Lima - que atuava no Instituto de Doenças Marítimas e Tropicais de Hamburgo desde 1909 - publicados no Jornal do Commercio reforçam a tese de Garambone sobre a neutralidade da imprensa carioca em um primeiro momento da guerra. Segundo Silva, o médico justificou a sua iniciativa de publicar textos pró-Alemanha na imprensa brasileira para desmentir a "campanha de inverdades, intrigas e calúnias, motivadas pela inveja, ressentimento e preocupação com o rápido progresso da Alemanha" (2015: 638). Segundo André Felipe Cândido da Silva, os artigos de Rocha Lima procuravam ser um contraponto às notícias veiculadas pelas agências francesa e inglesa, denunciando as contradições na propagada aliada que, ao retratar a guerra como uma luta da civilização e da liberdade contra a barbárie e o autoritarismo, deixava de mencionar a presença nessa mesma aliança da Rússia czarista, autoritária e atrasada. Assim, os argumentos contra a Alemanha não tinham fundamento, eram apenas "preconceitos e ideias vagas", afirmava Rocha Lima (Silva, 2015: 648). Segundo André Felipe, o médico aproximava-se do discurso dos intelectuais alemães, que denunciavam também a utilização pelos aliados de negros e eslavos como soldados, o que era uma contradição à ideia de que representavam os fiadores da civilização. As publicações do médico no jornal cessaram no final de 1914, já no ano seguinte, o periódico adotaria uma posição cada vez mais aliadófila, inclusive publicando boletins diários da LBA.

Sobre a imprensa nesse período, devemos ressaltar a importante iniciativa de jornalistas de Portugal, Brasil e Espanha que trouxe uma abordagem comparativa da imprensa nesses países, até então inédita. Fazemos referência a Balas de papel: a imprensa ilustrada e a Grande Guerra (1914-1918). Estudos sobre revistas de Portugal, Brasil e Espanha, publicada em 2015. As jornalistas Ana Regina Rêgo e Ranielle Leal Moura (2015) analisaram de forma geral a atuação de jornalistas, intelectuais e literatos na imprensa brasileira, classificando os seus discursos como uma verdadeira "guerra de papel", marcada por "estratégias anti-éticas", em que predominavam as posições a favor da guerra e dos aliados, mas que não eram de forma alguma uma unanimidade ou consenso. 0 estudo não traz grandes novidades sobre tema, mas ressalta o clima belicoso dentre a intelectualidade brasileira, bem como a predominância de uma opinião aliadofila. 
Ponto também percebido por Carlos Roberto de Melo Almeida (2017), que analisou com afinco os boletins semanais de Júlio Mesquita, publicados no jornal Estado de S. Paulo, o matutino da família Mesquita. Segundo Almeida, o jornal destacou-se na imprensa brasileira por sua cobertura da guerra justamente pelo fato de publicar semanalmente os comentários de seu próprio diretor com base nos telegramas vindos da Europa, nos relatos de jornais europeus e nas correspondências de amigos. Através de seus Boletins, Júlio Mesquita dava como certa a vitória da França e de seus aliados logo no início da guerra, além de conferir ao conflito o sentido de uma cruzada da civilização liberal contra o militarismo alemão. Contrastando com a análise de Garambone, no caso do periódico paulista, o posicionamento a favor dos aliados não foi fruto de maturação demorada, mas ocorreu de forma imediata à deflagração da guerra.

Outra característica importante, perceptível em pesquisas recentes, é a análise da imprensa fora do eixo Rio-São Paulo, como os trabalhos de Márcio de Oliveira (2012 e 2018) sobre a imprensa local em Curitiba e sua relação com os imigrantes alemães. Primeiramente, Oliveira destaca as diferentes relações entre as comunidades de imigrantes no Rio Grande do Sul e no Paraná, ponto importante, pois, a entrada do Brasil na guerra ao lado dos aliados desencadeou uma série de eventos violentos, sendo estes observados muito mais em Porto Alegre do que em Curitiba. Com relação à imprensa, Oliveira afirma que até meados de 1917, os principais jornais curitibanos seguiram a linha fixada pelos jornais de circulação nacional publicados na capital, porém, com publicação de eventuais artigos elogiosos para com a Alemanha e a comunidade alemã residente na cidade. E mesmo quando a imprensa nacional se voltou contra a Alemanha, foi possível perceber no âmbito da imprensa curitibana uma diferenciação entre os inimigos alemães e os imigrantes alemães residentes no Brasil. Oliveira conclui que o "perigo alemão" não foi alvo de muitas preocupações, mesmo tendo o conflito despertado uma onda de patriotismo na sociedade curitibana, caracterizada como uma sociedade extremamente multiétnica.

A imprensa regional também foi alvo da dissertação de Maria Dionéia Paula da Rosa (2017), que analisou o jornal riograndense A Federação. Segundo a autora, o fato de o jornal pertencer ao Partido Republicano Rio-Grandense ditou o seu posicionamento em consonância com o governo brasileiro. E mesmo na distante Belém, capital do estado do Pará, a guerra se fez presente através da imprensa. Segundo Ana Lúcia dos Santos, na capital paraense, o progresso econômico advindo da exportação da borracha contribuiu para o desenvolvimento de um jornalismo "vigoroso, moderno do ponto de vista de forma e conteúdo, em sintonia não só com acontecimentos locais e nacionais, mas também articulado com as grandes agendas da América e Europa" (2016: 290). Ao analisar os jornais A Folha do Norte, Estado do Pará e A Tarde, Rosa concluiu que, de uma forma geral, a imprensa paraense caminhou gradativamente para um posicionamento pró-aliado, seguindo a tendência da grande imprensa nacional, mas também influenciada pela presença de uma 
significativa colônia portuguesa em Belém. Todavia, houve alguns contrapontos, como a publicação por parte do jornal $A$ Tarde de editoriais pró-Alemanha, confrontando a disseminação de opinião aliadofilia na sociedade paraense. Segundo Rosa, tal discurso tinha conexões com as denúncias de contrabando de sementes de seringueiras por parte de ingleses para plantio em suas colônias da Ásia e que contribuiu para a queda dos preços do produto brasileiro no mercado internacional.

Por fim, resta destacar os trabalhos que procuram pensar os impactos culturais da guerra no Brasil a partir das revistas ilustradas. Com suas colunas sociais sobre o incipiente cenário cinematográfico ou com seus poemas-piada e caricaturas mordazes, as revistas semanais ilustradas tratavam de assuntos variados, como o cotidiano da cidade, sendo uma de suas características centrais o humor. Conquistaram uma fatia do pequeno público leitor e tornaram-se uma espécie de "coqueluche da nova burguesia urbana" como bem observou Sevcencko (1995: 119), principalmente devido à utilização em larga escala da fotografia.

A importância dessa narrativa visual sobre guerra é destacada primeiramente em um artigo de Marialva Barbosa, publicado na coletânea Balas de papel: a imprensa ilustrada e a Grande Guerra (1914-1918). Estudos sobre revistas de Portugal, Brasil e Espanha, já citada. Barbosa destaca como o segmento, que experimentava uma expressiva variação nas primeiras décadas do século XX, foi essencial para personalizar a guerra, representada em inúmeras fotografias e desenhos, com a fixação dos "rostos dos atores políticos que se constituíam naquele presente estendido como personagens de uma história futura” (2015).

Outro trabalho sobre as representações da guerra em uma revista ilustrada é a pesquisa de Fernanda Arouca sobre a revista O Malho (1914-1918). Segundo Arouca, o conflito marcou presença nas páginas da revista desde o início, acompanhado de duras críticas, que ressaltavam a importância de o Brasil manter sua neutralidade e seu papel de liderança na América do Sul (2017: 103). Em um primeiro momento, a análise de $O$ Malho, especialmente das caricaturas, aponta em uma direção já apresentada pela literatura: a desilusão com as potências europeias que se digladiavam como bárbaras. Todavia, em um segundo momento, em meados de 1917, as páginas da revista são tomadas pela onda patriótica, nacionalista e militarista que varreram o país. Nesse ponto, Arouca remete à ideia de que a ruptura ou desilusão com relação à cultura europeia deve ser relativizada. No caso, se há uma reorientação dos debates sobre identidade nacional, deve-se, todavia, ter em conta que "a Europa e, principalmente, o seu legado cultural não deixaram de fazer parte das referências brasileiras entre 1914 e 1918" (8). As conclusões de Arouca retomam uma questão já colocada nesse artigo: a coexistência de discursos acerca da desilusão ou ruptura com outros que procuravam reforçar os vínculos culturais brasileiros à civilização representada pelas nações europeias. Enfim, cabe destacar que Arouca deu continuidade aos estudos sobre circulação e propaganda da Primeira Guerra Mundial no Brasil, com foco no sistema de censura instituído no momento pelo governo brasileiro. 
A ideia da guerra como uma oportunidade para repensar a identidade nacional aparece discutida também no artigo de Rogério Souza Silva e Silvia Capanema de Almeida, publicado na coletânea La Gran Guerra en América Latina. Una historia conectada. Através da análise de caricaturas publicadas nas principais revistas ilustradas da capital, os autores reforçam a ideia de que "velha e deteriorada pela barbárie do conflito, a Europa começava a perder espaço na nova ordem mundial aos olhos dos cartunistas brasileiros" (2018: 284). Todavia, destacam que a imagem de nação construída no momento, ou "autoimagem brasileira", iria oscilar entre três pontos centrais: "o desconforto com a fragilidade bélica e política do país, as críticas à falta de informação e alienação dos brasileiros e a expressão de relativo prazer por estar fora do campo de batalha" (280).

Já o perfil aliadófilo da imprensa ilustrada é novamente reforçado por Ana Regina Rego, Antonio Carlos Holfeldt e Ranielle Leal Moura em artigo sobre a revista ilustrada paulista A Cigarra. Segundo os autores, a revista foi uma das que mais investiu em narrativas visuais sobre a guerra. Um discurso visual que sensibilizou "por meio da apresentação das crueldades, sobretudo, dos alemães" (2020: 230), com a utilização mais de pinturas do que de fotografias. Segundo os autores, a revista procurou manter certa imparcialidade no início do conflito, porém, a partir de outubro de 1914, são percebidas "construções negativas dos alemães e de seus aliados", sendo o exército aliado representado "combatendo com muita coragem e força e os exércitos inimigos, no caso, os alemães e aliados, por sua vez, desaparecem das cenas visuais do ponto de vista de uma representação imagética, passando a ser apenas mencionados nas legendas" (230).

Por fim, considerando o variado e extenso universo de periódicos ilustrados, concluímos apontando a clara necessidade de mais estudos de cunho comparativo.

\section{Aspectos conclusivos}

A partir do rápido panorama apresentado, podemos concluir que os estudos sobre os impactos culturais da Primeira Guerra Mundial no Brasil vêm crescendo significativamente, especialmente a partir dos anos 2010. 0 contexto comemorativo do centenário da Primeira Guerra pode ser considerado um dos elementos que contribuiu para essa nova onda de trabalhos, influenciando, por

21 Encontramos referência à pesquisa desenvolvida no âmbito do Programa Nacional de Apoio à Pesquisa da Biblioteca Nacional pelo historiador Cristiano Enrique de Brum, que tinha como objetivo analisar comparativamente posicionamentos e representações da guerra e da nação nas revistas Careta, D.Quixote, Fon-Fon!, O Malho e Revista da Semana. A pesquisa, sob o título "O Brasil e a Primeira Guerra Mundial através das revistas ilustradas brasileiras (1914-1918)", foi contemplada em dezembro 2020 com uma bolsa de pesquisa, na categoria "bolsista doutor" no âmbito do Programa Nacional de Apoio à Pesquisa da Biblioteca Nacional. Porém, como não encontramos nenhum artigo ou livro publicado, acreditamos que a pesquisa ainda não foi concluída. Como referência, ver https://www.bn.gov.br/producao/ documentos/brasil-primeira-guerra-mundial -atraves-revistas-ilustradas. 
exemplo, o patrocínio à pesquisa do tema a partir de instituições como FCRB e Biblioteca Nacional. Porém, como observamos na primeira parte deste artigo, os ventos que alteraram profundamente as análises sobre a Primeira Guerra começaram a soprar bem antes, ainda nos anos 1990. Agregando tais fatores, chegamos a alguns produtos expressivos dessas mudanças historiográficas como a coletânea La Gran Guerra em América Latina. Una historia conectada, publicada em 2018, bem como a realização de eventos internacionais como o I Workshop. Guerras Globais, impactos locais. A Primeira Guerra Mundial na Argentina e no Brasil, em 26 de outubro de $2020{ }^{22}$

Sobre a produção brasileira, podemos verificar que os múltiplos impactos culturais da guerra no Brasil alimentaram tanto uma incipiente desilusão com o paradigma europeu de civilização e cultura quanto um reforço de laços com a cultura latina difundida, principalmente, a partir da propaganda de guerra francesa, possibilitando o surgimento de significativas e variadas formas de nacionalismo. Vale acrescentar ainda, que no pós-guerra tais vínculos assumem inclusive uma nova natureza, como lembrou Mauricio Barreto Alvarez Parada (2014) em sua resenha sobre o livro de Olivier Compagnon, ao fazer referência aos diálogos entre movimentos vanguardistas europeus e movimentos modernistas tanto no Brasil quanto na Argentina. Com relação à imprensa, uma das temáticas mais abordadas pelos novos estudos brasileiros, percebemos que, se há uma rápida difusão de um discurso pró-aliado, ele não é de forma alguma unânime, havendo inúmeras vozes dissonantes que remetem às especificidades locais, bem como às características da rica $\mathrm{e}$ variada imprensa brasileira do período.

22 O evento foi organizado pelo Grupo de Estudos Históricos da Guerra (GEHiGue), pelo Programa de Pós-Graduação em História Social da Universidade Federal do Rio de Janeiro (UFRJ) e pela Faculdade do Exército da Universidade de Defesa Nacional (FE-UNDEF). Devido à pandemia de COVID-19, o evento foi realizado de forma remota. Para mais informações sobre o evento, ver https://gehigue.ar/. 


\section{Q Bibliografia}

" Albino, D. (2015). A Dialética de doutrinas francesa e norte-americana no Exército Brasileiro: O caso da Força Expedicionária Brasileira [Dissertação de mestrado, Universidade Federal do Estado do Rio de Janeiro].

" Almeida, C. R. (2017). A Grande Guerra (1914-1918) e os boletins semanais de Júlio Mesquita [Dissertação de mestrado, Universidade Estadual Paulista]. https://repositorio. unesp.br/handle/11449/152224.

" Arouca, F. (2017). As representações da Primeira Guerra Mundial (1914-1918) [Dissertação de mestrado, Universidade Federal do Rio de Janeiro].

" Arouca, F. (s.d.), Para além das trincheiras: narrativa, propaganda e censura da Primeira Guerra Mundial no Brasil (1914-1918) [Material de qualificação de doutorado, Universidade Federal do Rio de Janeiro].

" Audoin-Rouzeau, S. e Becker, A. (2000). 14-18, retrouver la Guerre. Gallimard.

" Audoin-Rouzeau, S. et al. (2009). La Grand Guerre des musiciens. Symétrie.

" Barbosa, M. (2015). Revistas e Guerra: a 1a. Guerra Mundial nas revistas críticas ilustradas brasileiras em J. P. Souza, Balas de Papel: a imprensa ilustrada e a Grande Guerra (1914-1918). Estudos sobre revistas de Portugal, Brasil e Espanha. Media XXI.

" Barros, J. (2011). A Nova História Cultural - considerações sobre o seu universo conceitual e seus diálogos com outros campos históricos. Cadernos de História, 12(16), 38-63.

" Becker, A. (2014). Avant-propos en F. Maindreville y S. Etcharry (dir.), La Gran Guerre en musique. Vie et création musicales en France pendant la Première Guerre mondiale. P.I.E. Peter Lang.

"Claro Pires, L. (2013). Intelectuais nas trincheiras: a Liga Brasileira pelos Aliados e o debate sobre a Primeira Guerra Mundial (1914-1919) [Dissertação de mestrado, Universidade do Estado do Rio de Janeiro].

" Claro Pires, L. (2020). Invencível Alemanha: os discursos germanófilos entre a intelectualidade brasileira durante a Primeira Guerra Mundial (1914-1919) [Projeto de pesquisa de doutorado, Universidade Federal do Rio de Janeiro].

" Compagnon, O. (2011). Guerre mondiale et construction nationale. Argentins et Brésiliens face au suicide de l'Europe (1914-1939) [Thèse de habilitation à diriger des Recherches, Université Paris I - Sorbonne].

" Compagnon, O. (2014). O adeus à Europa: a América Latina e a Grande Guerra. Rocco Digital.

" Compagnon, O. et al. (2018). Introducción en La Gran Guerra en América Latina. Una historia conectada. CEMCA.

"Correia, S. (2014). Cem anos de historiografia da Primeira Guerra Mundial: entre história transnacional e política nacional. Topoi, 15(29), 650-673.

" Crossley, P. (2008). What is global history?. Polity Press.

" Daróz, C. (2016). O Brasil na Primeira Guerra Mundial. A longa travessia. Contexto.

"Dehne, P. (2014). How important was Latin America to the First World War?. Iberoamericana, 14(53), 151-164.

" Fagundes, L. (2017). Música e guerra: impactos da Primeira Guerra Mundial no cenário musical carioca. Revista Brasileira de História, 37(76). http://dx.doi.org/10.1590/180693472017v37n76-02. 
" Fussell, P. (1975). The Great War and Modern Memory. Oxford University Press.

" Garambone, S. (2003). A primeira Guerra Mundial e a imprensa brasileira. Mauad.

"Hopkins, A. (2006). Global History. Interactions between the Universal and the Local. Palgrave Macmillan.

" Hynes, S. (1991). A War Imagined. The Great War and English Culture. Bodley Head.

" Isnenghi, M. (1970). II mito della Grande Guerra: da Marinetti a Malaparte. Laterza.

" Mattos, H. (2012). Além do Voto: cidadania e participação política na Primeira República brasileira em L. M. Schwarczs (ed.), História do Brasil Nação: a abertura para o mundo, 1889-1930. Objetiva.

" McCann, F. (2007). Soldados da Pátria: história do exército brasileiro, 1889-1937. Companhia das Letras.

" Molina, M. (2015). História dos jornais no Brasil. Da era colonial à Regência (1500-1840). (Vol. 1). Companhia das Letras.

" Mosse, G. (1990). Fallen Soldiers: Reshaping the Memory of the World wars. Oxford University Press.

" Motta, M. (1992). A nação faz 100 anos: a questão nacional no Centenário da Independência. FGV Editora.

" Oliveira, L. L. (1990). A questão nacional na Primeira República. Brasiliense.

" Oliveira, M. (2012). A cidade de Curitiba e os imigrantes alemães durante a Primeira Guerra Mundial, uma análise da imprensa local. Cadernos CERU, 23(2), 175-202. https:// doi.org/10.11606/issn.2595-2536.v23i2p175-202.

"Oliveira, M. (2018). Los inmigrantes alemanes y sus descendientes durante la Primera Guerra Mundial en Curitiba (Brasil). Representaciones de germanofobia e integración en los periódicos locales, 1914-1917 en O. Compagnon et al., La Gran Guerra en América Latina. Una historia conectada. CEMCA.

" Olstein, D. (2014). Thinking History Globally. Palgrave Macmillan.

" Paddock, T. (2014). World War I and Propaganda. Brill.

Parada, M. (2014). O espelho quebrado. Topoi, 15(29), 690-693.

"Pereira, A. A. (2013). A imprensa durante a Primeira Guerra Mundial e a organização das notícias: do título à manchete. Jornal Alcar, 6 .

" Prost, A. (1998). Social e Cultural indissocialmente en J-P. Rioux e J-F. Sirinelli (dir.), Para uma história cultural. Estampa.

"Prost, A. e Winter, J. (2004). Penser la Grande Guerre. Un essai d'historiographie. Seuil.

"Rego, A. et al. (2020). Narrativas visuais sobre a Primeira Guerra na revista A Cigarra. Revista Brasileira de História da Mídia, 9(2), 209-232.

" Rego, A. y Leal, R. (2015). Guerra de Papel: confrontos sobre um conflito, atuação dos jornalistas, intelectuais e literatos na imprensa brasileira durante a primeira guerra mundial em J. P. Sousa, Balas de papel: a Imprensa Ilustrada e a Grande Guerra (19141918). Estudos Sobre Revistas de Portugal, Brasil e Espanha. Media XXI.

" Rinke, S. (2017). Latin America and the First World War. Cambridge University Press.

" Rosa, M. (2017). O cenário internacional sob o olhar da imprensa regional: o jornal A Federação e a Primeira Guerra Mundial [Dissertação, Universidade de Passo Fundo]. https://www.upf.br/ppgh/dissertacoes-defendidas/2017. 
" Roshwald, A. e Stites, R. (1999). European culture in the Great War. The arts, entertainment, and propaganda, 1914-1918. Cambridge University Press.

" Rousso, H. (2016). A última catástrofe: a história, o presente e o contemporâneo. FGV Editora.

"Santos, A. L. (2016). Imprensa brasileira no ocaso da belle époque: a Primeira Guerra Mundial sob o olhar dos jornais paraenses [Tese, Universidade Fernando Pessoa]. https:// bdigital.ufp.pt/handle/10284/5513.

" Sevcencko, N. (1995). Literatura como missão: Tensões sociais e criação cultural na Primeira República. (4⿳亠口了 ed.). Brasiliense.

" Sevcenko, N. (1992). Orfeu extático na metrópole. Companhia das Letras.

"Silva, A. (2015). Nas trincheiras do front intelectual Henrique da Rocha Lima e a Primeira Guerra Mundial no Jornal do Commercio. Varia Historia, 31(57), 635-671.

" Silva, R. e Almeida, S. (2018). La Primera Guerra Mundial en la caricatura brasileña: un campo de batallas ilustradas en O. Compagnon et al. (coord.), La Gran Guerra en América Latina. Una historia conectada. CEMCA.

"Skidmore, T. (2012). Preto no Branco. Raça e nacionalidade no pensamento brasileiro. Companhia das Letras.

" Siskind, M. (2015). The spectacle of War at a distance: Latin American Modernistas in World War I. Modern Languages Notes 130(2), 234-255.

"Sondhaus, L. (2014). A Primeira Guerra Mundial. História Completa. (1a ed.). Contexto.

"Tato, M. I. (2008). Nacionalismo e internacionalismo en la Argentina durante la Gran Guerra. Projeto História, 36, 49-62.

" Tato, M. I. (2014). Luring neutrals. Allied and German Propaganda in Argentina during the First World War en T. Paddock, World War I and Propaganda. Brill.

"Vega Jiménez, P. (2013). La guerra como espectáculo mediático. La prensa centroamericana en la Gran Guerra (1917). Historia y Comunicación Social, 18, 43-61.

"Watkins, G. (2003). Proof through the night. Music and the Great War. University of California Press.

\section{Sobre o autor}

Luciana Pessanha Fagundes é formada em História pela Universidade Federal do Rio de Janeiro (UFRJ), fez mestrado em História Social na mesma instituição, possui doutorado em História, Política e Bens Culturais, realizado na Fundação Getúlio Vargas (FGV). Possui pós-doutorado em História da Música, realizado na Escola de Música da UFRJ, onde também atuou como docente. Seu segundo pós-doutorado foi realizado na Fundação Casa de Rui Barbosa (FCRB), onde pesquisou o cenário musical brasileiro durante a Primeira Guerra Mundial. Atualmente, realiza seu terceiro pós-doutorado no Programa de Pós-Graduação em História Social da UFRJ, com a pesquisa intitulada "Canções de guerra: a mobilização brasileira na Primeira Guerra Mundial". 


\section{Sobre la autora}

Luciana Pessanha Fagundes se graduó en Historia en la Universidad Federal de Río de Janeiro (UFRJ), hizo su Maestría en Historia Social en la misma institución, posee un Doctorado en Historia, Política y Bienes Culturales, realizado en la Fundación Getúlio Vargas (FGV). Tiene un postdoctorado en Historia de la Música, realizado en la Escuela de Música de la UFRJ, donde también se desempeñó como docente. Hizo su segundo postdoctorado en la Fundación Casa de Rui Barbosa (FCRB), donde investigaó la escena musical brasileña durante la Primera Guerra Mundial. Actualmente realiza su tercer postdoctorado en el Programa de Posgrado en Historia Social de la UFRJ, con la investigación titulada "Canciones de guerra: la movilización brasileña en la Primera Guerra Mundial”.

\section{About the author}

Luciana Pessanha Fagundes holds a degree in History from the Federal University of Rio de Janeiro (UFRJ), a Master's degree in Social History from the same institution, and a PhD in History, Politics and Cultural Property from the Getúlio Vargas Foundation (FGV). She holds a postdoctorate in Music History, from the School of Music of UFRJ, where she worked as a professor. Her second post-doctorate was held at the Casa de Rui Barbosa Foundation (FCRB), where she researched the Brazilian music scene during World War I. Currently, she is taking her third post-doctorate in the UFRJ's Postgraduate Program in Social History, with the project entitled "Songs of war: the Brazilian mobilization in the First World War". 